\title{
Bayesian Network-Based Process Downtime Cost Determination of an Industrial Plant
}

\author{
Kevin M. Suliva, Senen D. Fenomeno
}

\begin{abstract}
Industrial plants utilize sensitive equipment to produce their products and meet their financial targets. Equipment downtime caused by power quality issues such as voltage sag affects production and entails cost hence poses a threat to their ability to deliver their financial objectives. This research aims to determine the response of industrial equipment to sag events and quantify the downtime cost caused by interruption in the production process. The study used the voltage tolerance curve to determine the individual equipment response to sag events and the Bayesian Network to establish the network structure of the production process. The probability of process interruption and the associated downtime losses was computed using a mathematical software. The research shows a strong relationship between the equipment's response to voltage sag events and the production downtime cost and highlights the importance of the immunity of equipment to voltage sags.
\end{abstract}

Index Terms- Industrial Process, Sensitive Equipment, Voltage Sag, Voltage Tolerance Curve, Bayesian Network

\section{INTRODUCTION}

Power Quality is relatively a new concept in the new industry today. This is due to increasing use of electronic equipment in automation of process of its system that requires good quality of source from the utility to its industrial end users. The equipment in the process are connected in a definite manner that will produce a specific output on a certain process. Thus, the tripping of one equipment in the process can cause the whole process to trip that is integral to its output. One of the most common cause of tripping of the equipment is the faults on the distribution network that causes voltage sags. It is the most common power quality disturbance and deteriorating form of its kind in terms of its effect on equipment. Due to sensitivity of the equipment connected in the industrial plant, it may or may not cause a tripping of equipment in the process and thus, this particular disturbance can cause significant impact in terms of its reliability of equipment in a certain industrial process where it is configured to produce certain output which in turn cause financial loss of the plant.

Previous studies [3],[6],[7] describes the severity and effect of voltage sag in a process in terms of its output process parameters and this is since each equipment is classified as sensitive in terms of its nature and built and the criterion it produced is critical to the output of the said plant.

However, this previous research studies did not tackle the

response of the equipment in that particular process to trip give a particular event of voltage sag and instead it focuses on the decline of its output process parameters. This leaves the question what is the relationship in terms of its response of each equipment in the process.

On the other hand, authors also determined the cost of downtime in one particular process that is correlated in its downtime to determine the efficiency of the said plant due to an interruption due to voltage sag [10],[3]. The need also to determine the downtime cost for a given response of an equipment for an event of voltage sag aside from its season is critical in order to assess the effect of this disturbances to the economic output of the plant in terms of its outcome to the equipment involved.

International Council on Large electric systems or CIGRE sets the standard [4] in the voltage dip immunity of a particular equipment and installation and its given economic and financial impact. It is in which the standard used the concept of Process Immunity time to distinguish between process and equipment failure and it allows better economic assessment of impact of voltage sags on industrial installations. However, the equipment specified in the standard is only limited to four industrial equipment (PLC, Personal Computer, Contactor, Adjustable Speed Drive) which needed to be updated in order to be relevant to fit a certain process being utilized in the industry today to produce an output.

The objective of this research study is to determine the performance of sensitive equipment in a certain industrial process when subjected to power quality disturbances such as voltage sags and the associated downtime cost as a result of process disruption. Using the equipment's voltage tolerance curve, the response to voltage sag events will be determined. The probability of process disruption will then be calculated using Bayesian Network. After which, the downtime cost will be calculated.

The study premise and setting are conducted on the industrial end user. This is since industrial end user will suffer significant amount of economic loss for an interruption or disruption in their process. Other power quality disturbances that causes short duration interruption such as transients and harmonics are not considered in the study that has other characteristics such as waveform and phase shift angle. This is since these disturbances are more concerned with the phase shift angle characteristic rather than magnitude and duration which is counted as per event.
Revised Version Manuscript Received on 10 September, 2019.

Kevin M. Suliva, [1] Graduate Studies, School of EECE, Mapua University, Philippines. (Email: kevin.suliva@yahoo.com)

Senen D. Fenomeno, Graduate Studies, School of EECE, Mapua University, Philippines. (Email: sdfenomeno@gmail.com) 


\section{DATA GATHERING}

The subject setting for the research is in a generic pharmaceutical manufacturing plant and drug development center that manufactures sterile and non-sterile products. The plant is known for researching, producing and manufacturing generic droplets that is being used in several hospitals and clinics and in the country. The plant experience process interruption caused by power quality disturbances such as transients, harmonics and voltage imbalance from the distribution network and from their electrical system as well but the most detrimental and severe form of this disturbances is voltage sags, which is caused by starting of motors being used in pumping from deep well for purified water, lightning that hit the distribution lines, and switching off heavy loads for the past years which cost the plant up to nearly Php $900,000.00(\$ 17,647.00)$ per year.

\section{A. Equipment and Process Evaluation}

The plant is consist of two identical phases which are intertwined together that is being used in sterile production process, in which are running in parallel with each other, one can produce each type of droplets or both at the same time namely, ophthalmic and otic drops, which is compose of similar types of equipment that is being use in different processes. The process flow of each two phases can be shown in figure 1:

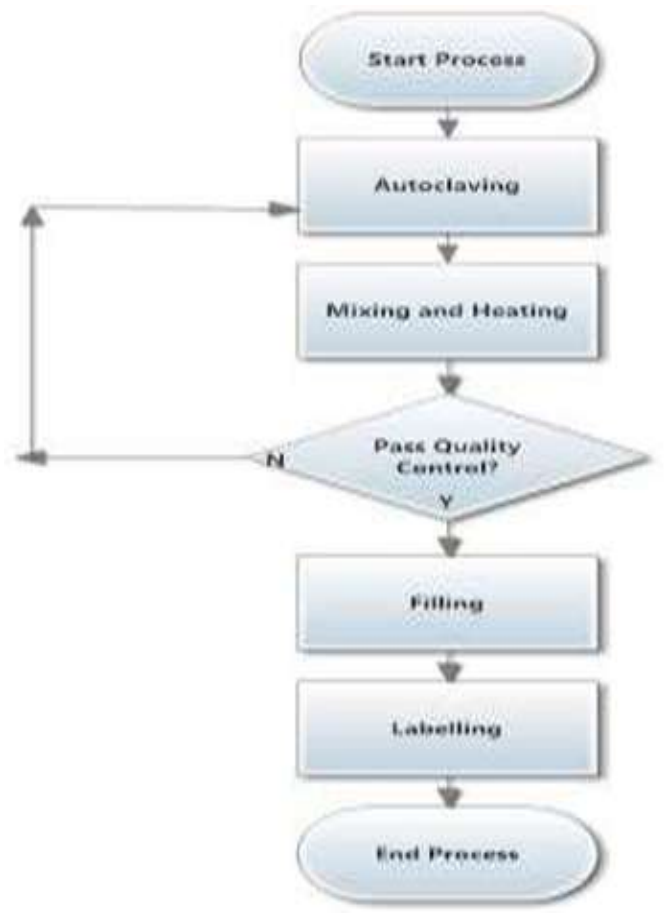

Figure 1: Process flow for the sterile production

In each phase, the raw materials are being pass through process of autoclaving (sterilizing), mixing, heating, filling and finally, packaging and labelling the droplet bottles. The process for each phase has equivalent equipment being utilize and use. Plotting the process and its related equipment in the form of nodes of network structure of probability using Bayesian network is shown in figure 2:

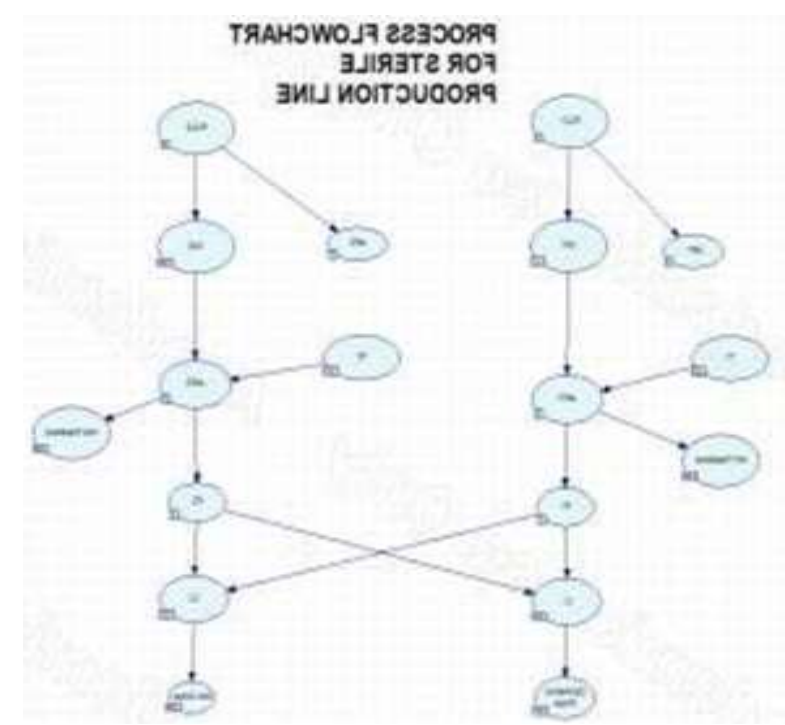

Figure 2: Network Structure composed of nodes of the two phases

In which each of process and its equivalent equipment in the form of nodes is given by:

Autoclaving Process:

VA- Vacuum Autoclave (Major Equipment)

MP-Mini Printer (Subcomponent)

PLC-Programmable Logic Controller (Subcomponent)

Mixing and Heating Process:

JMT-Jacketed Mixing Tank (Major Equipment)

T-Thermo controller (Subcomponent)

Filling Process:

F-Filling Machine (Major Equipment)

Labelling Process:

L-Labelling Machine (Major Equipment)

In which the two output nodes are the major product output of each phase namely the Ophthalmic or eye drops and the Otic or ear drops.

The network structure then is compose of 14 equipment nodes, in which 7 identical equipment are in each phase of the production line, 2 feedback nodes for each phase, and two output nodes which represents the major product output of each phase of the sterile production line namely, Ophthalmic and Otic drops, for a total of 18 nodes and in which each of the nodes will be converted to the trip probability of each equipment in the process and its conditional probability in relation with its parent and child node given an event of voltage sag.

The specifications given by the manufacturer of each equipment in the process to the maintenance and engineering personnel of the plant which indicates the maximum and minimum magnitude (percent per unit) and time (cycle) threshold will be used to plot the voltage tolerance curve of each equipment similar in the figure below. 


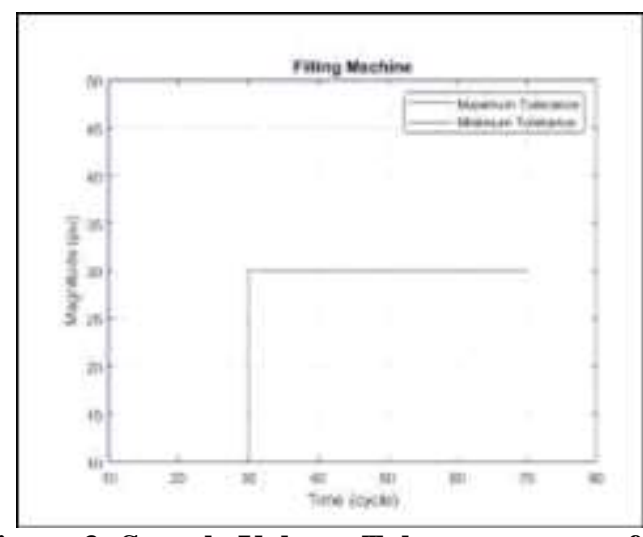

Figure 3: Sample Voltage Tolerance curve of an equipment

\section{B. Voltage Sag Performance and Evaluation}

Alongside with the evaluation of the equipment in each process of each phases, the researcher determines the historical data of voltage sag events of the plant. The sag event data encompasses four years, starting from the year 2014 in which the plant suffers severe nuisance tripping of equipment in the process which results in downtime losses up to the year 2017. The voltage sag events will be converted in the form of scatter plot gathered as an example on figure below.

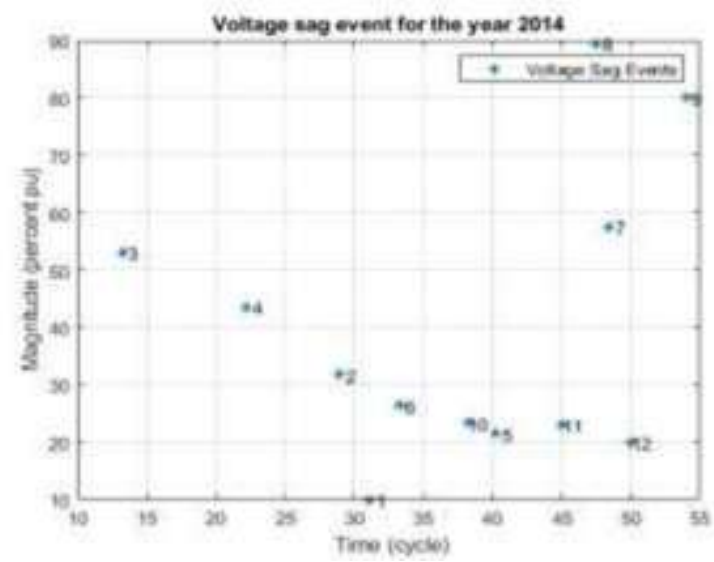

Figure 4: Voltage Sag Events in the form of scatter plot

\section{Development of the Network Structure}

The voltage tolerance curve of each equipment in the process and the given voltage sag events in the form of scatter plot, will be now be correlated in order to determine the response probability of each event of the voltage sag. In which can be categorized into:

1. TRIP Condition - in which the given probability will be set to $p=1.00$

2. UNCERTAIN Condition - in which the given probability will be set to $\mathrm{p}=0.50$

3. OPERATE Condition - in which the given probability will be set to $\mathrm{p}=0.50$

Using the response probability of each equipment in the process, it will be the input to the network structure composed of nodes in which it signifies their condition dependencies with each other to determine the marginal probability distribution of each output products and using the formula (1) of joint probability of the network structure given below:

$\left(1_{-}, 1_{-}, 1_{-}, 1_{-}, 1_{-}, 1_{-}, 1_{-}, 1_{-}, 2_{-}, 2_{-}, 2_{-}, 2_{-}, 2_{-}, 2_{-}, 2_{-}\right.$, $\left.1_{-}, 2_{-}\right)=\left(1_{-}\right) *\left(1_{-} \mid 1_{-}\right) *\left(1_{-} \mid 1_{-}\right) *\left(1_{-}\right) *\left(1_{-} \mid 1_{-}\right) *$ $\left(1_{-} \mid 1_{-}\right) *\left(1_{-} \mid 1_{-}\right) *\left(1_{-} \mid 1_{-}, 2_{-}\right) *\left(1_{-} \mid 1_{-}\right) *\left(2_{-}\right) *(2$ $\left.\mid 2_{-}\right) *\left(2_{-} \mid 2_{-}\right) *\left(2_{-}\right) *\left(2_{-} \mid 2_{-}\right) *\left(2_{-} \mid 2_{-}\right) *\left(2_{-} \mid 2_{-}\right) *$

$\left(2_{-} \mid 1_{-}, 2_{-}\right) *\left(2_{-} \mid 2_{-}\right)(1)$

where:

PLC1_t and PLC2_t - trip probability of PLC for phase 1 and 2 respectively

MP1_t and MP2_t - trip probability of Mini Printer for phase 1 and 2 respectively

VA1_t and VA2_t - trip probability of Vacuum Autoclave for phase 1 and 2 respectively

T1_t and T2_t - trip probability of Thermo controller for phase 1 and 2 respectively

JMT1_t and JMT2_t - trip probability of Jacketed Mixing Tank for phase 1 and 2 respectively

VA1Feedback_t and VA2Feedback_t- trip probability of feedback nodes for Vacuum Autoclave for phase 1 and 2 respectively

F1_t and F2_t - trip probability of Filling Machine for phase 1 and 2 respectively

L1_t and L2_t - trip probability of Labelling Machine for phase 1 and 2 respectively

$\mathrm{O} 1 \_\mathrm{u}$ and $\mathrm{O} 2 \_\mathrm{u}$ - probability to unfinish Ophthalmic drops

(O1) and Otic drops (O2)

The conditional probability of the Bayesian network is given by equation 2 :

$\mathrm{P}(\mathrm{A} \mid \mathrm{B})=(\mathrm{P}(\mathrm{B} \mid \mathrm{A}) \mathrm{P}(\mathrm{A})) / \mathrm{P}(\mathrm{B})$

where:

$\mathrm{P}(\mathrm{A} \mid \mathrm{B})$ - posterior probability $\mathrm{P}(\mathrm{B})$-Predictor Prior

Probability

P(A)-Class Prior Probability $\mathrm{P}(\mathrm{B} \mid \mathrm{A})$ -

likelihood probability

In which it is the conditional probability at which the equipment in the lower process (child node) will trip given the equipment in the upper process (parent node) is tripped due to voltage sag which signifies that the predictor prior probability is set to TRIP condition. For example, $\mathrm{P}\left(\mathrm{L} 1 \_\mathrm{t} \mid \mathrm{F} 1 \_\mathrm{t}\right)$ implies the conditional probability of Labelling Machine 1 (Class Prior Probability) to trip given the condition that the Filling Machine 1 (Predictor Prior probability) has been tripped due to voltage sag events. In the same way, the conditional probability of each equipment to trip under normal condition without voltage sag event is signified by the condition that the predictor prior probability is set to OPERATE condition. For example, P(L1_t $\left.\mid \mathrm{F} 1 \_\mathrm{o}\right)$ implies the conditional probability of Labelling Machine 1 to trip given the condition that the Labelling Machine 1 (Class Prior Probability) to trip despite the Filling Machine 1 (Predictor Prior probability) is running under normal condition. The value for these conditional probabilities will be derived from historical records of each equipment breakdown and failure with no interruption and voltage sag event happens.

Using variable elimination derived from joint probability distribution (equation 1) to determine the marginal probabilities distribution or the probability to miss or unfinish the target production of a certain product or output ( $\mathrm{P}\left(\mathrm{O} 1 \_\mathrm{u}\right)$ and $\left.\mathrm{P}\left(\mathrm{O} 2 \_\mathrm{u}\right)\right)$.

Published By: 


\section{BAYESIAN NETWORK-BASED PROCESS DOWNTIME COST DETERMINATION OF AN INDUSTRIAL PLANT}

Using the equation above and Figure 2 as the probability network structure for Bayesian Network to determine the marginal probability distribution of each output for each voltage sag event for the past years, the downtime losses will now be asses according to the configuration of the equipment in the process.

D. Assessment of the Cost of downtime of equipment and process

Using the configuration of the major equipment in each process to support the marginal probability of each output and its given response for an event of voltage sag, the downtime cost will then resolve per event of voltage sag $n$ from its performance and profile and total annual cost of downtime losses. This is to determine which characteristic of voltage sag that is causing significant financial losses to the process and to the sterile production process based on the response of each equipment in the process and as a whole to voltage sag event.

The total downtime cost will per event of voltage sag and is given by equation 3 :

$$
\operatorname{COD}_{n}=\left(\text { Cost }_{\text {direct }}+\text { Cost }_{\text {indirect }}\right)-\text { Cost }_{\text {Salvages }}
$$

where:

$\mathrm{COD}_{n}-$

Cost of downtime per event of sag number n, Philippine peso

Cost $_{\text {direct }}$ -

Direct financial loss, Philippine peso

Cost $_{\text {indirect }}$ -

Indirect financial loss, Philippine peso

Cost $_{\text {Salvage }}$ -

Salvage value of the product, Philippine peso

The cost of downtime per event of voltage sag for each year is determined by equation 4 :

$$
C O D_{\text {annual }}=\sum_{n=1}^{n} C O D_{n}
$$

Where:

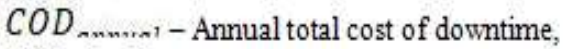

Philippine Peso

$C O D_{n}$ - Cost of dorntime per event of sag number

n, Philippine Peso

n-sag event number

\section{RESULTS AND DISCUSSION}

Using the response from correlation of voltage tolerance curve and voltage sag events for a given year will be the input in the Bayesian network in the form of network structure of nodes, the marginal probabilities or the probability to miss or unfinish the target production of a certain output and the number of equipment per response is given by table I to IV.

\section{Table I: Marginal Probability Distribution for the year} 2014

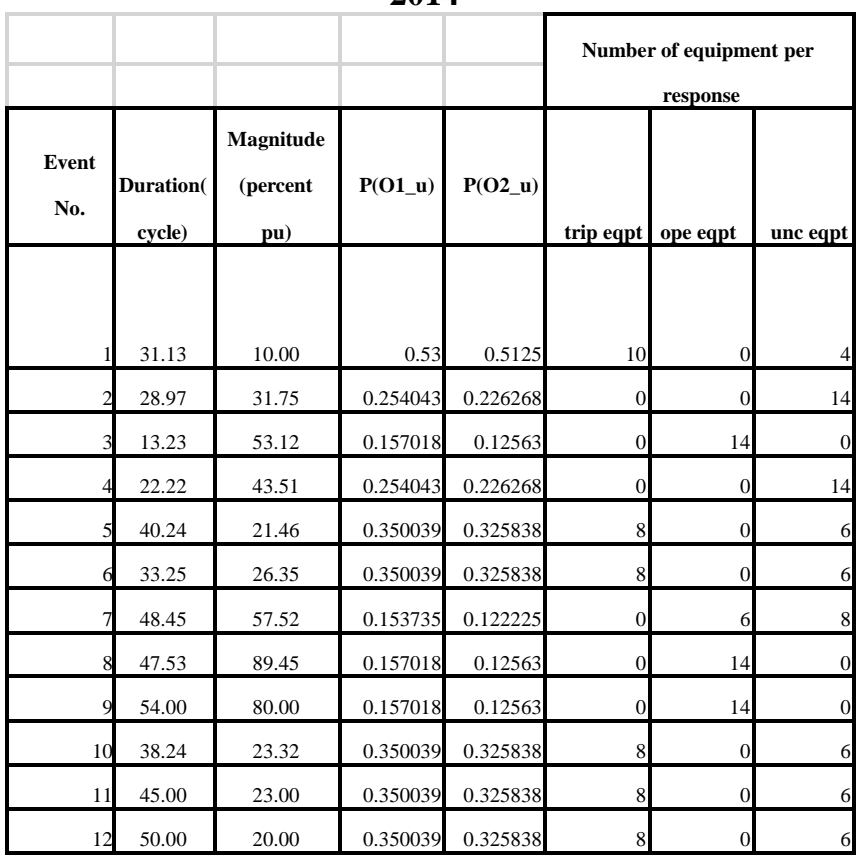

Table II: Marginal Probability Distribution for the year

\begin{tabular}{|c|c|c|c|c|c|c|c|}
\hline & & & & & & & \\
\hline & & & & & Number & $\begin{array}{l}\text { of equipm } \\
\text { response }\end{array}$ & ent per \\
\hline $\begin{array}{c}\text { Event } \\
\text { No. }\end{array}$ & $\begin{array}{c}\text { Duration } \\
\text { cycle) }\end{array}$ & $\begin{array}{c}\text { Magnitude } \\
\text { (percent } \\
\text { pu) } \\
\end{array}$ & $\mid \mathbf{P}\left(\mathbf{O} 1 \_\mathbf{u}\right)$ & $\mathbf{P}\left(\mathbf{O} 2 \_\mathbf{u}\right)$ & trip eqpt & ope eqpt & unc eqp \\
\hline 1 & 32.10 & 10.00 & 0.53 & 0.5125 & 10 & 0 & 4 \\
\hline 2 & 28.97 & 33.54 & 0.254043 & 0.226268 & 0 & 0 & 14 \\
\hline 3 & 12.42 & 52.36 & 0.157018 & 0.12563 & 0 & 14 & 0 \\
\hline 4 & 21.36 & 42.45 & 0.254043 & 0.226268 & 0 & 0 & 14 \\
\hline 5 & 41.25 & 21.21 & 0.350039 & 0.325838 & 8 & 0 & 6 \\
\hline 6 & 34.25 & 25.24 & 0.350039 & 0.325838 & 6 & 0 & 8 \\
\hline 7 & 48.78 & 56.32 & 0.153735 & 0.122225 & 0 & 6 & 8 \\
\hline 8 & 47.53 & 89.45 & 0.157018 & 0.12563 & 0 & 14 & 0 \\
\hline 9 & 55.32 & 81.23 & 0.157018 & 0.12563 & 0 & 14 & 0 \\
\hline 10 & 55.21 & 51.79 & 0.154127 & 0.122632 & 0 & 2 & 12 \\
\hline 11 & 50.00 & 90.00 & 0.157018 & 0.12563 & 0 & 14 & 0 \\
\hline 12 & 54.79 & 85.00 & 0.157018 & 0.12563 & 0 & 14 & 0 \\
\hline
\end{tabular}
2015 
Table III: Marginal Probability Distribution for the year 2016

\begin{tabular}{|c|c|c|c|c|c|c|c|}
\hline \multirow[b]{2}{*}{$\begin{array}{l}\text { Event } \\
\text { No. }\end{array}$} & \multirow[b]{2}{*}{$\begin{array}{c}\text { Duration(cyc } \\
\text { le) } \\
\end{array}$} & \multirow[b]{2}{*}{$\begin{array}{l}\text { Magnitude(pe } \\
\text { rcent pu) }\end{array}$} & \multirow[b]{2}{*}{ P(O1_u) } & \multirow[b]{2}{*}{$\mathbf{P}\left(\mathbf{O 2} \_\mathbf{u}\right)$} & \multicolumn{3}{|c|}{$\begin{array}{c}\text { Number of equipment per } \\
\text { response }\end{array}$} \\
\hline & & & & & trip eqpt & ope eqpt & unc eqpt \\
\hline 1 & 52.12 & 88.550 & 0.157018 & 0.12563 & 0 & 14 & 0 \\
\hline 2 & 25.23 & 82.46 & 0.157018 & 0.12563 & 0 & 14 & 0 \\
\hline 3 & 29.68 & 23.00 & 0.267293 & 0.240011 & 2 & 0 & 12 \\
\hline 4 & 35.62 & 75.64 & 0.157018 & 0.12563 & 0 & 14 & 0 \\
\hline 5 & 41.42 & 62.24 & 0.153735 & 0.122225 & 0 & 8 & 6 \\
\hline 6 & 51.90 & 53.00 & 0.240793 & 0.212525 & 0 & 2 & 12 \\
\hline 7 & 33.00 & 45.25 & 0.254043 & 0.226268 & 0 & 0 & 14 \\
\hline 8 & 45.41 & 23.73 & 0.350039 & 0.325838 & 8 & 0 & 6 \\
\hline 9 & 24.00 & 54.57 & 0.207937 & 0.178445 & 0 & 4 & 10 \\
\hline 10 & 45.56 & 23.29 & 0.350039 & 0.325838 & 8 & 0 & 6 \\
\hline 11 & 51.24 & 21.27 & 0.350039 & 0.325838 & 8 & 0 & 6 \\
\hline 12 & 42.00 & 35.00 & 0.254043 & 0.226268 & 0 & 0 & 14 \\
\hline
\end{tabular}

Table IV: Marginal Probability Distribution for the year 2017

\begin{tabular}{|c|c|c|c|c|c|c|c|}
\hline \multirow[b]{2}{*}{$\begin{array}{l}\text { Event } \\
\text { No. }\end{array}$} & \multirow[b]{2}{*}{$\begin{array}{l}\text { Duration( } \\
\text { cycle) } \\
\end{array}$} & \multirow[b]{2}{*}{$\begin{array}{c}\text { Magnitude } \\
\text { (percent } \\
\text { pu) } \\
\end{array}$} & \multirow[b]{2}{*}{ P(O1_u) } & \multirow[b]{2}{*}{$\mathbf{P}\left(\mathbf{O 2} \_u\right)$} & \multicolumn{3}{|c|}{$\begin{array}{c}\text { Number of equipment per } \\
\text { response } \\
\end{array}$} \\
\hline & & & & & trip eqpt & ope eqpt & unc eqpt \\
\hline 1 & 25.000 & 33.250 & 0.254043 & 0.226268 & 0 & 0 & 14 \\
\hline 2 & 12.230 & 23.240 & 0.249962 & 0.222035 & 0 & 6 & 8 \\
\hline 3 & 42.000 & 27.241 & 0.350039 & 0.325838 & 8 & 0 & 6 \\
\hline 4 & 32.547 & 85.940 & 0.157018 & 0.12563 & 0 & 14 & 0 \\
\hline 5 & 52.324 & 45.235 & 0.254043 & 0.226268 & 0 & 0 & 14 \\
\hline 6 & 32.147 & 24.740 & 0.31633 & 0.290874 & 4 & 0 & 10 \\
\hline 7 & 27.850 & 52.247 & 0.154127 & 0.122632 & 0 & 2 & 12 \\
\hline 8 & 38.241 & 23.325 & 0.350039 & 0.325838 & 8 & 0 & 6 \\
\hline 9 & 20.130 & 57.896 & 0.157018 & 0.12563 & 0 & 12 & 2 \\
\hline 10 & 32.456 & 56.956 & 0.153735 & 0.122225 & 0 & 8 & 6 \\
\hline 11 & 42.563 & 23.278 & 0.350039 & 0.325838 & 8 & 0 & 6 \\
\hline 12 & 35.630 & 25.324 & 0.350039 & 0.325838 & 8 & 0 & 6 \\
\hline
\end{tabular}

It can be shown from these that as the number of equipment in the process operates increase so the value of the probability of missing the target production of an output decrease. This is due to the fact that the target production to produce an Ophthalmic and Otic drops relies heavily on the operation and response of the equipment in the process. Also, the relationship between the number of equipment that responds in UNCERTAIN condition to the fixed response (TRIP and OPERATE) to the probability of missing the target production of an output is somewhat weaker and this is since each equipment has an uncertain region that affects the response of each equipment to a particular event of voltage sag that is integral to the productivity and production for a certain output.

Assuming the value of response of the major equipment in the process, namely, the vacuum autoclave, mixing tank, filling machine and labelling machine, and their respective marginal probability distribution of each output for each event of voltage sag, the value for the minimum and maximum downtime losses will be assess. Table V to VIII displays the marginal probability distribution of each event of voltage sag and their respective downtime losses for each event of voltage sag per given year. 
BAYESIAN NETWORK-BASED PROCESS DOWNTIME COST DETERMINATION OF AN INDUSTRIAL PLANT

Table V (a) and (b) : Maximum and Minimum downtime loss for the year 2014

\begin{tabular}{|c|c|c|c|c|c|c|c|c|c|c|c|}
\hline $\begin{array}{r}\text { Event } \\
\text { No. }\end{array}$ & $\mathbf{P}\left(01 \_\mathrm{u}\right)$ & $\mathrm{P}\left(\mathbf{0 2} \_\mathrm{u}\right)$ & Starved & Disrupted & Scrap Cost & $\begin{array}{l}\text { Energy } \\
\text { Cost }\end{array}$ & Restart Cost & Direct Cost & Indirect Cost & Salvage Cost & $\begin{array}{c}\text { Cost of } \\
\text { Downtime }\end{array}$ \\
\hline 1 & 0.53 & 0.5125 & 465.89 & 205.54 & $61,038.50$ & 785.84 & $1,973.07$ & $64,468.84$ & $46,881.67$ & $6,020.00$ & $105,330.51$ \\
\hline & 0.254043 & 0.226268 & 465.89 & 205.54 & $61,038.50$ & 785.84 & $1,973.07$ & $64,468.84$ & $46,881.67$ & $6,020.00$ & $105,330.51$ \\
\hline 3 & 0.157018 & 0.12563 & - & - & - & - & - & - & - & - & - \\
\hline 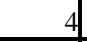 & 0.254043 & 0.226268 & 465.89 & 205.54 & $61,038.50$ & 785.84 & $1,973.07$ & $64,468.84$ & $46,881.67$ & $6,020.00$ & $105,330.51$ \\
\hline & 0.350039 & 0.325838 & 465.89 & 205.54 & $61,038.50$ & 785.84 & $1,973.07$ & $64,468.84$ & $46,881.67$ & $6,020.00$ & $105,330.51$ \\
\hline 6 & 0.350039 & 0.325838 & 465.89 & 205.54 & $61,038.50$ & 785.84 & $1,973.07$ & $64,468.84$ & $46,881.67$ & $6,020.00$ & $105,330.51$ \\
\hline & 0.153735 & 0.122225 & 301.46 & 369.97 & $61,038.50$ & 756.05 & $1,973.07$ & $64,439.05$ & $33,336.67$ & - & $97,775.72$ \\
\hline 8 & 0.157018 & 0.12563 & - & - & - & - & - & - & - & - & - \\
\hline 9 & 0.157018 & 0.12563 & - & - & - & - & - & - & - & - & - \\
\hline 10 & 0.350039 & 0.325838 & 465.89 & 205.54 & $61,038.50$ & 785.84 & $1,973.07$ & $64,468.84$ & $46,881.67$ & $6,020.00$ & $105,330.51$ \\
\hline 11 & 0.350039 & 0.325838 & 465.89 & 205.54 & $61,038.50$ & 785.84 & $1,973.07$ & $64,468.84$ & $46,881.67$ & $6,020.00$ & $105,330.51$ \\
\hline 12 & 0.350039 & 0.325838 & 465.89 & 205.54 & $61,038.50$ & 785.84 & $1,973.07$ & $64,468.84$ & $46,881.67$ & $6,020.00$ & $105,330.51$ \\
\hline & & & & & & & & & & TOTAL & $940,419.80$ \\
\hline
\end{tabular}

(a)

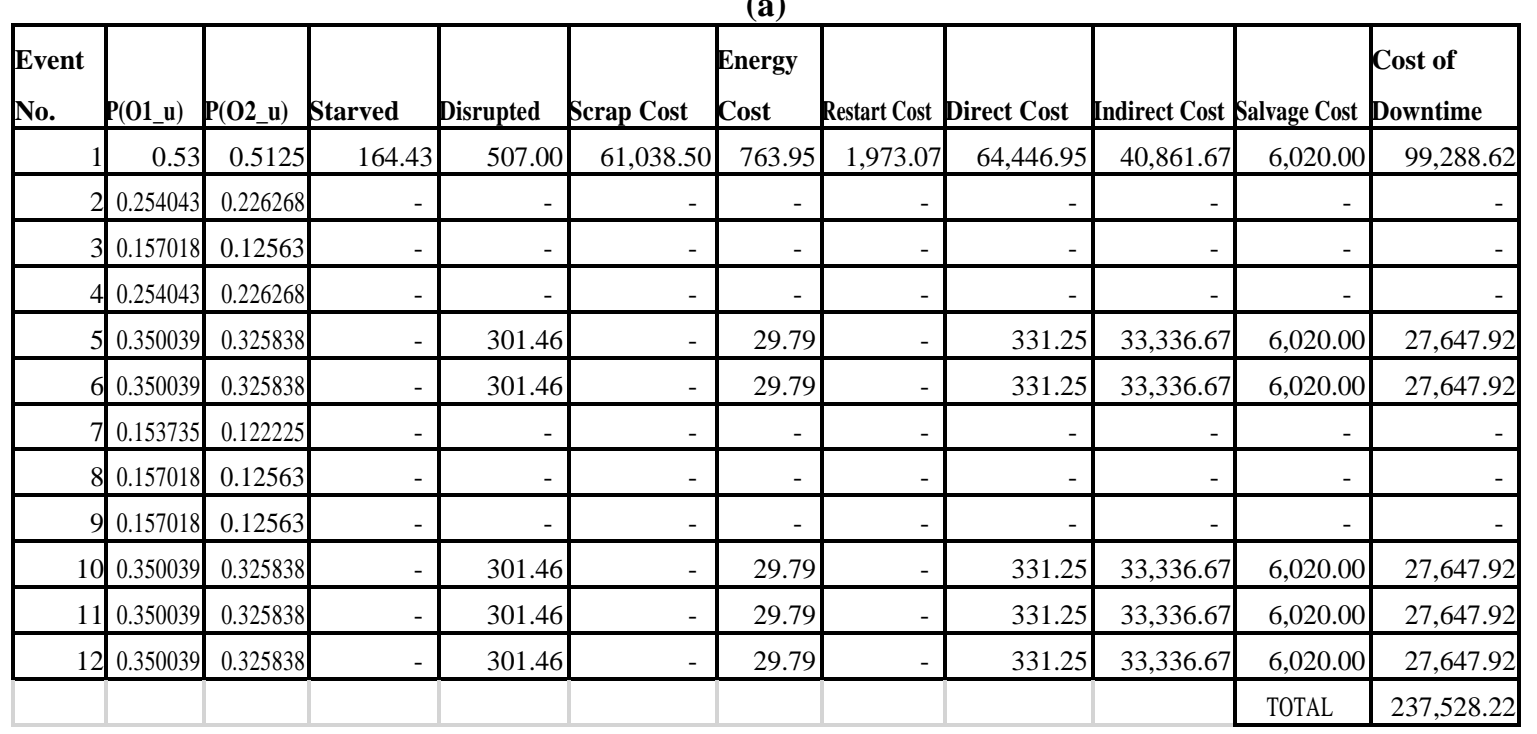

(b)

Table VI (a) and (b) : Maximum and Minimum downtime loss for the year 2015

\begin{tabular}{|c|c|c|c|c|c|c|c|c|c|c|c|}
\hline $\begin{array}{r}\text { Event } \\
\text { No. } \\
\end{array}$ & $\mathbf{P}\left(\mathbf{0 1} \_\mathbf{u}\right)$ & $\mathbf{P}\left(\mathbf{O 2} \_\mathbf{u}\right)$ & Starved & Disrupted & Scrap Cost & $\begin{array}{r}\text { Energy } \\
\text { Cost } \\
\end{array}$ & Restart Cost & Direct Cost & Indirect Cost & Salvage Cost & $\begin{array}{c}\text { Cost of } \\
\text { Downtime } \\
\end{array}$ \\
\hline 1 & 0.530000 & 0.512500 & 521.79 & 230.20 & $55,360.50$ & 925.43 & $3,627.41$ & $60,665.33$ & $56,295.00$ & $5,460.00$ & $111,500.33$ \\
\hline 2 & 0.254043 & 0.226268 & 521.79 & 230.20 & $55,360.50$ & 925.43 & $3,627.41$ & $60,665.33$ & $56,295.00$ & $5,460.00$ & $111,500.33$ \\
\hline 3 & 0.157018 & 0.125630 & 337.63 & 184.16 & $55,360.50$ & 77.33 & - & $55,959.62$ & $39,460.00$ & $5,460.00$ & $89,959.62$ \\
\hline 4 & 0.254043 & 0.226268 & 521.79 & 230.20 & $55,360.50$ & 925.43 & $3,627.41$ & $60,665.33$ & $56,295.00$ & $5,460.00$ & $111,500.33$ \\
\hline 5 & 0.350039 & 0.325838 & 521.79 & 230.20 & $55,360.50$ & 925.43 & $3,627.41$ & $60,665.33$ & $56,295.00$ & $5,460.00$ & $111,500.33$ \\
\hline 6 & 0.350039 & 0.325838 & 521.79 & 230.20 & $55,360.50$ & 925.43 & $3,627.41$ & $60,665.33$ & $56,295.00$ & $5,460.00$ & $111,500.33$ \\
\hline 7 & 0.153735 & 0.122225 & 337.63 & 414.36 & $55,360.50$ & 890.35 & $3,627.41$ & $60,630.25$ & $44,010.00$ & - & $104,640.25$ \\
\hline 8 & 0.157018 & 0.125630 & - & - & - & - & - & - & - & - & - \\
\hline 9 & 0.157018 & 0.125630 & - & - & - & - & - & - & - & - & - \\
\hline 10 & 0.154127 & 0.122632 & 153.47 & 598.52 & $55,360.50$ & 916.12 & $3,627.41$ & $60,656.02$ & $51,745.00$ & $5,460.00$ & $106,941.02$ \\
\hline 11 & 0.157018 & 0.125630 & - & - & - & - & - & - & - & - & - \\
\hline 12 & 0.157018 & 0.125630 & - & - & - & - & - & - & - & - & - \\
\hline & & & & & & & & & & TOTAL & $859,042.54$ \\
\hline
\end{tabular}

(a) 
International Journal of Recent Technology and Engineering (IJRTE) ISSN: 2277-3878, Volume-8, Issue-2S11, September 2019

\begin{tabular}{|c|c|c|c|c|c|c|c|c|c|c|c|}
\hline $\begin{array}{r}\text { Event } \\
\text { No. } \\
\end{array}$ & $\mathbf{P}\left(01 \_\mathbf{u}\right)$ & $\mathbf{P}\left(\mathbf{0 2} \_\mathbf{u}\right)$ & Starved & Disrupted & Scrap Cost & $\begin{array}{r}\text { Energy } \\
\text { Cost } \\
\end{array}$ & Restart Cost & Direct Cost & Indirect Cost & Salvage Cost & $\begin{array}{c}\text { Cost of } \\
\text { Downtime } \\
\end{array}$ \\
\hline 1 & 0.530000 & 0.512500 & 184.16 & 567.83 & $55,360.00$ & 899.65 & $3,627.41$ & $60,639.05$ & $50,835.00$ & $5,460.00$ & $106,014.05$ \\
\hline 2 & 0.254043 & 0.226268 & - & - & - & - & - & - & - & - & - \\
\hline 3 & 0.157018 & 0.125630 & 337.63 & 184.16 & $55,360.50$ & 77.33 & - & $55,959.62$ & $39,460.00$ & $5,460.00$ & $89,959.62$ \\
\hline 4 & 0.254043 & 0.226268 & - & - & - & - & - & - & - & - & - \\
\hline 5 & 0.350039 & 0.325838 & - & 337.63 & - & 35.08 & - & 372.71 & $44,010.00$ & $5,460.00$ & $38,922.71$ \\
\hline 6 & 0.350039 & 0.325838 & - & 337.63 & - & 35.08 & - & 372.71 & $44,010.00$ & $5,460.00$ & $38,922.71$ \\
\hline 7 & 0.153735 & 0.122225 & - & - & - & - & - & - & - & - & - \\
\hline 8 & 0.157018 & 0.125630 & - & - & - & - & - & - & - & - & - \\
\hline 9 & 0.157018 & 0.125630 & - & - & - & - & - & - & - & - & - \\
\hline 10 & 0.154127 & 0.122632 & - & - & - & - & - & - & - & - & - \\
\hline 11 & 0.157018 & 0.125630 & - & - & - & - & - & - & - & - & - \\
\hline 12 & 0.157018 & 0.125630 & - & - & - & - & - & - & - & - & - \\
\hline & & & & & & & & & & TOTAL & $273,819.09$ \\
\hline
\end{tabular}

(b)

Table VII (a) and (b) : Maximum and Minimum downtime loss for the year 2016

\begin{tabular}{|c|c|c|c|c|c|c|c|c|c|c|c|}
\hline $\begin{array}{c}\text { Event } \\
\text { No. } \\
\end{array}$ & $\mathbf{P}(\mathbf{0 1} \mathbf{u})$ & $\mathbf{P}(\mathbf{O} 2$ _ $\mathbf{u})$ & Starved & $\begin{array}{c}\text { Disrupte } \\
\text { d }\end{array}$ & Scrap Cost & $\begin{array}{c}\text { Energy } \\
\text { Cost }\end{array}$ & $\begin{array}{c}\text { Restart } \\
\text { Cost }\end{array}$ & Direct Cost & $\begin{array}{c}\text { Indirect } \\
\text { Cost } \\
\end{array}$ & $\begin{array}{l}\text { Salvage } \\
\text { Cost }\end{array}$ & $\begin{array}{c}\text { Cost of } \\
\text { Downtime } \\
\end{array}$ \\
\hline & 0.157018 & 0.12563 & - & - & - & - & - & - & - & - & - \\
\hline & 0.157018 & 0.12563 & & & & & & - & & & - \\
\hline & 0.267293 & 0.240011 & 557.15 & 245.80 & $66,716.50$ & $1,110.69$ & $3,203.66$ & $71,833.80$ & $54,368.33$ & $6,580.00$ & $119,622.13$ \\
\hline & 0.157018 & 0.12563 & - & - & - & - & - & - & - & - & - \\
\hline & 0.153735 & 0.122225 & 360.51 & 442.44 & $66,716.50$ & $1,068.58$ & $3,203.66$ & $71,791.69$ & $39,563.33$ & - & $111,355.02$ \\
\hline & 0.240793 & 0.212525 & 163.87 & 639.08 & $66,716.50$ & $1,099.52$ & $3,203.66$ & $71,822.63$ & $48,885.00$ & $6,580.00$ & $114,127.63$ \\
\hline & 0.254043 & 0.226268 & 557.15 & 245.80 & $66,716.50$ & $1,110.69$ & $3,203.66$ & $71,833.80$ & $54,368.33$ & $6,580.00$ & $119,622.13$ \\
\hline & 0.350039 & 0.325838 & 557.15 & 245.80 & $66,716.50$ & $1,110.69$ & $3,203.66$ & $71,833.80$ & $54,368.33$ & $6,580.00$ & $119,622.13$ \\
\hline & 0.207937 & 0.178445 & 163.87 & 639.08 & $66,716.50$ & $1,099.52$ & $3,203.66$ & $71,822.63$ & $48,885.00$ & $6,580.00$ & $114,127.63$ \\
\hline 10 & 0.350039 & 0.325838 & 557.15 & 245.80 & $66,716.50$ & $1,110.69$ & $3,203.66$ & $71,833.80$ & $54,368.33$ & $6,580.00$ & $119,622.13$ \\
\hline 11 & 0.350039 & 0.325838 & 557.15 & 245.80 & $66,716.50$ & $1,110.69$ & $3,203.66$ & $71,833.80$ & $54,368.33$ & $6,580.00$ & $119,622.13$ \\
\hline 12 & 0.254043 & 0.226268 & 557.15 & 245.80 & $66,716.50$ & $1,110.69$ & $3,203.66$ & $71,833.80$ & $54,368.33$ & $6,580.00$ & $119,622.13$ \\
\hline & & & & & & & & & & TOTAL & $1,057,343.06$ \\
\hline
\end{tabular}

(a)

\begin{tabular}{|c|c|c|c|c|c|c|c|c|c|c|c|}
\hline $\begin{array}{r}\text { Event } \\
\text { No. } \\
\end{array}$ & $\mathrm{P}\left(\mathrm{O} 1 \_\mathrm{u}\right)$ & $\mathrm{P}\left(\mathrm{O} 2 \_\mathrm{u}\right)$ & Starved & $\begin{array}{c}\text { Disrupte } \\
\mathrm{d}\end{array}$ & Scrap Cost & $\begin{array}{r}\text { Energy } \\
\text { Cost } \\
\end{array}$ & $\begin{array}{r}\text { Restart } \\
\text { Cost } \\
\end{array}$ & Direct Cost & $\begin{array}{c}\text { Indirect } \\
\text { Cost }\end{array}$ & \begin{tabular}{|} 
Salvage \\
Cost
\end{tabular} & $\begin{array}{c}\text { Cost of } \\
\text { Downtime }\end{array}$ \\
\hline 1 & 0.157018 & 0.12563 & - & - & - & - & - & - & - & - & - \\
\hline & 0.157018 & 0.12563 & - & - & - & - & - & - & - & - & - \\
\hline & 0.267293 & 0.240011 & - & 196.64 & - & 30.94 & - & 227.58 & $34,080.00$ & $6,580.00$ & $27,727.58$ \\
\hline & 0.157018 & 0.12563 & - & - & - & - & - & - & - & - & - \\
\hline & 0.153735 & 0.122225 & - & - & - & - & - & - & - & - & - \\
\hline & 0.240793 & 0.212525 & - & - & - & - & - & - & - & - & - \\
\hline & 0.254043 & 0.226268 & - & - & - & - & - & - & - & - & - \\
\hline & 0.350039 & 0.325838 & - & 360.51 & - & 42.11 & - & 402.62 & $39,563.33$ & $6,580.00$ & $33,385.95$ \\
\hline 9 & 0.207937 & 0.178445 & - & - & - & - & - & - & - & - & - \\
\hline 10 & 0.350039 & 0.325838 & - & 360.51 & - & 42.11 & - & 402.62 & $39,563.33$ & $6,580.00$ & $33,385.95$ \\
\hline 11 & 0.350039 & 0.325838 & - & 360.51 & - & 42.11 & - & 402.62 & $39,563.33$ & $6,580.00$ & $33,385.95$ \\
\hline 12 & 0.254043 & 0.226268 & - & - & - & - & - & - & - & - & - \\
\hline & & & & & & & & & & TOTAL & $127,885.43$ \\
\hline
\end{tabular}

(b) 
BAYESIAN NETWORK-BASED PROCESS DOWNTIME COST DETERMINATION OF AN INDUSTRIAL PLANT

Table VIII (a) and (b) : Maximum and Minimum downtime loss for the year 2017

\begin{tabular}{|c|c|c|c|c|c|c|c|c|c|c|c|}
\hline $\begin{array}{c}\text { Event } \\
\text { No. }\end{array}$ & $\mathbf{P}\left(\mathbf{0 1} \_\mathbf{u}\right)$ & $\mathbf{P}\left(\mathbf{O} 2 \_\mathbf{u}\right)$ & Starved & Disrupted & Scrap Cost & $\begin{array}{c}\text { Energy } \\
\text { Cost }\end{array}$ & $\begin{array}{r}\text { Restart } \\
\text { Cost } \\
\end{array}$ & Direct Cost & Indirect Cost & $\begin{array}{r}\text { Salvage } \\
\text { Cost } \\
\end{array}$ & $\begin{array}{c}\text { Cost of } \\
\text { Downtime } \\
\end{array}$ \\
\hline 1 & 0.254043 & 0.226268 & 583.26 & 257.32 & $72,394.50$ & 996.09 & $3,243.21$ & $77,474.38$ & $55,955.00$ & $7,140.00$ & $126,289.38$ \\
\hline 2 & 0.249962 & 0.222035 & - & - & - & - & - & - & - & - & - \\
\hline 3 & 0.350039 & 0.325838 & 583.26 & 257.32 & $72,394.50$ & 996.09 & $3,243.21$ & $77,474.38$ & $55,955.00$ & $7,140.00$ & $126,289.38$ \\
\hline 4 & 0.157018 & 0.125630 & - & - & - & - & - & - & - & - & - \\
\hline 5 & 0.254043 & 0.226268 & 583.26 & 257.32 & $72,394.50$ & \begin{tabular}{|l|}
996.09 \\
\end{tabular} & $3,243.21$ & $77,474.38$ & $55,955.00$ & $7,140.00$ & $126,289.38$ \\
\hline 6 & 0.316330 & 0.290874 & 583.26 & 257.32 & $72,394.50$ & 996.09 & $3,243.21$ & $77,474.38$ & $55,955.00$ & $7,140.00$ & $126,289.38$ \\
\hline 7 & 0.154127 & 0.122632 & 583.26 & 257.32 & $72,394.50$ & 996.09 & $3,243.21$ & $77,474.38$ & $55,955.00$ & $7,140.00$ & $126,289.38$ \\
\hline 8 & 0.350039 & 0.325838 & 583.26 & 257.32 & $72,394.50$ & 996.09 & $3,243.21$ & $77,474.38$ & $55,955.00$ & $7,140.00$ & $126,289.38$ \\
\hline 9 & 0.157018 & 0.125630 & - & - & - & - & - & - & - & - & - \\
\hline 10 & 0.153735 & 0.122225 & 377.40 & 463.18 & $72,394.50$ & 958.32 & $3,243.21$ & $77,436.61$ & $39,890.00$ & - & $117,326.61$ \\
\hline 11 & 0.350039 & 0.325838 & 583.26 & 257.32 & $72,394.50$ & 996.09 & $3,243.21$ & $77,474.38$ & $55,955.00$ & $7,140.00$ & $126,289.38$ \\
\hline 12 & 0.350039 & 0.325838 & 583.26 & 257.32 & $72,394.50$ & 996.09 & $3,243.21$ & $77,474.38$ & $55,955.00$ & $7,140.00$ & $126,289.38$ \\
\hline & & & & & & & & & & TOTAL & $1,127,641.65$ \\
\hline
\end{tabular}

(a)

\begin{tabular}{|c|c|c|c|c|c|c|c|c|c|c|c|}
\hline $\begin{array}{c}\text { Event } \\
\text { No. } \\
\end{array}$ & P(O1_u) & P(O2_u) & Starved & Disrupted & Scrap Cost & $\begin{array}{r}\text { Energy } \\
\text { Cost } \\
\end{array}$ & $\begin{array}{c}\text { Restart } \\
\text { Cost }\end{array}$ & Direct Cost & Indirect Cost & $\begin{array}{c}\text { Salvage } \\
\text { Cost } \\
\end{array}$ & $\begin{array}{c}\text { Cost of } \\
\text { Downtime }\end{array}$ \\
\hline 1 & 0.254043 & 0.226268 & - & - & - & - & - & - & - & - & - \\
\hline 2 & 0.249962 & 0.222035 & - & - & - & . & - & - & - & - & - \\
\hline 3 & 0.350039 & 0.325838 & - & 377.40 & - & 37.76 & - & 415.16 & $39,890.00$ & $7,140.00$ & $33,165.16$ \\
\hline 4 & 0.157018 & 0.125630 & & & & & & - & & & - \\
\hline 5 & 0.254043 & 0.226268 & & & & & & - & & & - \\
\hline 6 & 0.316330 & 0.290874 & 411.71 & 171.55 & - & 10.02 & - & 593.28 & $32,750.00$ & - & $33,343.28$ \\
\hline 7 & 0.154127 & 0.122632 & & & & & & - & & & - \\
\hline 8 & 0.350039 & 0.325838 & - & 377.40 & - & 37.76 & - & 415.16 & $39,890.00$ & $7,140.00$ & $33,165.16$ \\
\hline 9 & 0.157018 & 0.125630 & & & & & & - & & & - \\
\hline 10 & 0.153735 & 0.122225 & & & & & & - & & & - \\
\hline 11 & 0.350039 & 0.325838 & - & 377.40 & - & 37.76 & - & 415.16 & $39,890.00$ & $7,140.00$ & $33,165.16$ \\
\hline \multirow[t]{2}{*}{12} & 0.350039 & 0.325838 & - & 377.40 & - & 37.76 & - & 415.16 & $39,890.00$ & $7,140.00$ & $33,165.16$ \\
\hline & & & & & & & & & & TOTAL & $166,003.92$ \\
\hline
\end{tabular}

It can be shown from the results table from 2014 to 2017 that the marginal probability distribution of $\mathrm{P}\left(\mathrm{O} 1_{-} \mathrm{u}\right)=$ 0.157018 and $\mathrm{P}\left(\mathrm{O} 2 \_\mathrm{u}\right)=0.12563$ results in no minimum and maximum downtime cost. This is due to the sense that all of the equipment in the process operates given a particular event of voltage sag and hence, will accumulate no downtime losses. Similarly, when all of the equipment in the process responds in an UNCERTAIN condition with equivalent marginal probability distribution of $\mathrm{P}\left(\mathrm{O} 1 \_\mathrm{u}\right)=0.254043$ and $\mathrm{P}\left(\mathrm{O} 2 \_\mathrm{u}\right)=0.226268$, the maximum downtime loss will be on its maximum value, That is Php 105,330.51 $(\$ 2,065.00)$ for the year 2014, Php 111,500.33 $(\$ 2,186.00)$ for the year 2015, Php 119,622.13 (\$2,345.00) for the year 2016 and Php $126,289.38(\$ 2,476.00)$ for the year 2017 and the minimum downtime loss will be zero. For the marginal probability distribution resulting from mixed response of OPERATE and UNCERTAIN response of the equipment, the maximum downtime cost will range from Php 104,640.25 (\$2,051.00) to $111,500.33(\$ 2,186.00)$ and the minimum downtime cost will zero per event of voltage sag. This is since assuming the entire UNCERTAIN response of equipment will be change to OPERATE condition and hence, no minimum downtime cost will be acquired. For the marginal probability distribution culminating from mixed response of TRIP and UNCERTAIN response of the equipment, the maximum downtime cost will range from $\mathrm{Php} 114,127.63$ (\$2,237.00) to $105,330.51$ (\$ $2,065.00)$ and the minimum downtime cost will range from Php 99,288.62 (\$1,946.00) to Php 0.00 per event of voltage sag. This is the maximum downtime cost the plant can incur since all the UNCERTAIN response of the equipment will be set to TRIP condition.

It can be shown that as the probability to miss the target production of Ophthalmic and Otic drops due to an event of voltage sag increases so is its equivalent maximum and minimum downtime cost for a given event of voltage sag. This is evident since the entire process and production relies on the operation of this machines and equipment to hit the target production of a certain output and product.

Also, it can be shown that as the number of equipment trip due to voltage sag increases so is its equivalent downtime cost since this is since it is where the production output relies on the operation of equipment in the process. It also be shown that as the number of equipment operates for an event of voltage sag increases, the downtime cost will be minimized in a certain manner and this is expected since the production line will be in full or partial operation when a certain number of equipment in the process operates.

Published By:

Blue Eyes Intelligence Engineering 


\section{CONCLUSION AND RECOMMENDATION}

This research establish that the uncertainty region that lies between the maximum and minimum boundaries in voltage tolerance curve is crucial part in the immunity and susceptibility of a sensitive equipment in a certain industrial process since it will give equipment manufacturers margin of adjustment for its protection to power quality disturbances such as voltage sags and also to adapt the sensitive equipment to an electrical system environment. It will also account for the maximum and minimum values of the downtime losses for each event of voltage sag. It is also concluded on this research that the downtime loss of the plant for an event of voltage sag relies on the production target of the plant's product output.

This shows that the economic and financial output of the plant relies on the target production of its product output and its required deliverable to the distributor. This research also established that the downtime cost of the industrial relies on the number of equipment that responds to a particular event of voltage sag. It implies that the operation and response of the sensitive equipment to disturbances such as voltage sag is crucial to the economics and financial output of the plant in terms of its losses. From this observation, this research establish that the immunity and protection of a sensitive equipment in an industrial process dictates how much the industrial plant will lose in terms of production target of its output products and financial output in terms of its losses. The researcher then suggests on extensive power quality survey before and after constructing an industrial plant to assure the feasibility of its supply and reliability. This study will raise awareness on the side of distribution utility and company to invest on power quality mitigation devices on distribution lines particularly near industrial parks and plants in which most of this sensitive equipment is being utilized and in which production target relies upon.

\section{REFERENCES}

1. Bollen M.H (2000). Understanding Power Quality Problems: Voltage Sag and Interruptions, 1st Edition, IEEE Press Series on Power Engineering (John Wiley \& Sons, Inc), Hoboken, New Jersey

2. Cebrian J.C, Camilo L., Matsuo N.M. , Arango H. (2005), Comparing the Monte Carlo and analytical methods to assess the risks of voltage sags disruptions, CIRED 200518th International Conference and Exhibition on Electricity Distribution, Turin, Italy

3. Cebrian J.C, Kagan N.,Milanovic J.V (2014), Probabilistic Assessment of Financial Losses in Distribution Network due to Fault Induced Process Interruptions Considering Process Immunity Time, IEEE Transactions on Power Delivery (Volume: 30, Issue 3, June 2015)

4. CIGRE/CIRED/UIE Joint Working Group (2010), Voltage Dip Immunity of Equipment and Installations

5. Djokic S.Z, Desmet J.,Vanalme G.,Milanovic J.V, Stockman K. (2005), Sensitivity of Personal Computers to Voltage Sags and Short Interruptions, IEEE Transactions on Power Delivery (Vol. 20, No. 1, January 2005), USA

6. Gupta C.P and Milanovic J.V. (2006), Probabilistic Methods for Counting Equipment Trips Due to Voltage Sags, 2006 International Conference on Probabilistic Methods Applied to Power Systems, Stockholm, Sweden

7. Joon Lee G.,Albu M.M,Heydt, G.T (2004), A Power Quality Index Based on Equipment Sensitivity, Cost and
Network vulnerability ,IEEE Transactions on Power Delivery (Vol. 19, No. 3, July 2004), USA

8. Kagan N. et al. (2004), Evaluating the risk of equipment disruption related to voltage sags, 2004 IEEE/PES Transmission and Distribution Conference and Exposition: Latin America, Sao Paulo, Brazil

9. Kyei J.,Ayyanar R.,Heydt G.,Thallam R.,Blevins J (2002), The Design of Power Acceptability Curve, IEEE Transactions on Power Delivery (Vol. 17, No. 3, July 2002), USA

10. Vegunta S.C and Milanovic J.V (2010), Estimation of Cost of Downtime of Industrial Process Due to Voltage Sags, IEEE Transactions of Power Delivery (Volume: 26, Issue 2, April 2011)

11. Xiao-Lu S, Yuan-bo L.,Ying W.,Xian-yong X. (2010), Equipment Failure Probability Evaluation Due to Voltage Sag Using Cloud Model, 2010 International Conference on Future power and Energy Engineering, Shenzhen, China. 